\title{
Women in neurosurgery: where does the United Kingdom stand?
}

\author{
Meriem Amarouche, MSc, FHEA, FRCS(SN), ${ }^{1}$ Micaela Uberti, MD, ${ }^{2}$ \\ Gwenllian Y. H. R. Evans, MBBS, BSc, ${ }^{3}$ and Navneet Singh, MSc, PhD, FRCSEd(NeuroSurg) ${ }^{2}$ \\ 'Department of Neurosurgery, John Radcliffe University Hospital, Oxford; 2Department of Neurosurgery, St. George's University \\ Hospital, London; and ' ${ }^{2}$ epartment of Neurosurgery, Royal London Hospital, London, United Kingdom
}

\begin{abstract}
Despite over half of medical students in the United Kingdom (UK) being female, women represent only a small proportion of the workforce in the traditional "male" specialties, including neurosurgery. There is increasing global attention to and awareness of gender discrimination in the workplace across several industries, including health care. The authors set out to explore the opinions and attitudes of UK neurosurgeons and neurosurgery trainees on gender issues via a large-scale national survey. The results highlight key perceptions and gaps in mentorship and leadership and provide ideas for change. This should be used as a foundation to delve deeper and to address specific questions in order to achieve a fairer, more meritocratic environment in which neurosurgeons can thrive.
\end{abstract}

https://thejns.org/doi/abs/10.3171/2020.12.FOCUS20957

KEYWORDS women in neurosurgery; gender gap; women in surgery

$\mathrm{W}$ OMEN have been present in neurosurgery history since the 15th century, with reports describing Turkish Tabibes extracting fetuses with hydrocephalus and macrocephaly. ${ }^{1}$ Four centuries later, in 1865 , England saw its first woman qualify as a doctor, with Elizabeth Garrett Anderson ${ }^{2}$ paving the way for all future generations of female physicians. It took another 74 years to see the first woman qualify as a neurosurgeon in the United Kingdom (UK). Diana Beck ${ }^{3}$ was trained by Hugh Cairns in Oxford and qualified in 1939.

Since then, there has been a real increase in the number of women graduating from medical schools in the UK. In 2018, the General Medical Council reported that $56 \%$ of all medical students were female. ${ }^{4}$ However, the number of women pursuing a surgical career is still lagging behind. Based on data from the Royal College of Surgeons of England (RCS Eng), the proportion of female consultant surgeons was only $3 \%$ in 1991 and $13.2 \%$ in $2020 .{ }^{5}$

Robert Spetzler's landmark paper in the field of women in neurosurgery ${ }^{6}$ sparked interest in the topic, but have things improved since its publication in 2011? Where does British neurosurgery stand in comparison to both other surgical specialties and international colleagues in terms of female representation?

With this study, we explored current perceptions and challenges in gender disparity in neurosurgery by conducting a large-scale, UK-wide survey to gather opinions of existing neurosurgeons and trainees on the matter. To our knowledge, this is the largest survey of its kind in the UK to date.

\section{Methods}

We designed a 15-question survey (Supplemental Survey), which we then distributed electronically via Survey Planet.com to all Society of British Neurological Surgeons (SBNS) and British Neurosurgical Trainees' Association (BNTA) members. Responses were gathered anonymously. We present a qualitative analysis of the data with descriptive statistics, performed using Microsoft Excel. We report median scores for the questions assessed with a Likert scale.

\section{Results}

We received 308 responses, of which 291 were from the UK. We excluded 17 respondents who were international members of SBNS. In total, 189 respondents were male, 91 were female, 10 did not disclose their gender, and 1 was of nonbinary gender. A breakdown of respondents by grade and gender is shown in Table 1.

ABBREVIATIONS BNTA = British Neurosurgical Trainees' Association; CT = core trainee; LTFT = less than full-time; NHS = National Health Service; RCS Eng = Royal College of Surgeons of England; SBNS = Society of British Neurological Surgeons; ST = specialist trainee; UK = United Kingdom.

SUBMITTED November 1, 2020. ACCEPTED December 28, 2020.

INCLUDE WHEN CITING DOI: 10.3171/2020.12.FOCUS20957. 
TABLE 1. Survey respondents by grade and gender

\begin{tabular}{lccccc}
\hline \multicolumn{1}{c}{ Grade } & Male & Female & PNTS & NBG & Total \\
\hline Consultant & $70(37 \%)$ & $21(23.1 \%)$ & $3(30 \%)$ & & $94(32.3 \%)$ \\
\hline Post-CCT fellow (or equivalent) & $20(10.6 \%)$ & $7(7.7 \%)$ & $2(20 \%)$ & & $29(10 \%)$ \\
\hline ST3-8 (or equivalent) & $57(30.2 \%)$ & $41(45.1 \%)$ & $2(20 \%)$ & $1(100 \%)$ & $101(34.7 \%)$ \\
\hline ST1-2 (or equivalent) & $24(12.7 \%)$ & $20(22 \%)$ & $1(10 \%)$ & & $45(15.5 \%)$ \\
\hline Retired consultant & $14(7.4 \%)$ & $2(2.2 \%)$ & & & $16(5.5 \%)$ \\
\hline PNTS & $4(2.1 \%)$ & & $2(20 \%)$ & & $6(2.1 \%)$ \\
\hline Total & 189 & 91 & 10 & 1 & 291 \\
\hline
\end{tabular}

$\mathrm{CCT}=$ certificate of completion of training; $\mathrm{NBG}=$ nonbinary gender; $\mathrm{PNTS}=$ prefer not to say.

\section{Relationship Status and Impact of Neurosurgery on Relationships}

Of the 280 respondents who disclosed their relationship status, $83.7 \%$ of men were married or in a long-term relationship versus $60.7 \%$ of women. Women were more likely to be single $(22.5 \%)$ than men $(9.8 \%)$. Although $81 \%$ of our respondents were in a long-term supportive relationship, $65.4 \%$ of men and $64.8 \%$ of women still felt that their relationship was impacted by their neurosurgical career. We received 167 qualitative responses describing the nature of that impact. Three respondents portrayed a positive impact, with neurosurgery being an impressive career that attracts partners. The remaining individuals all felt differently. The 5 most mentioned negative impacts of a neurosurgical career on their relationships were poor work-life balance, difficulties with childcare, strain on forming or maintaining relationships, working long and unpredictable hours, and lack of geographical stability.

\section{Children}

In total, 164 (56.4\%) respondents had children (including adult children). Excluding individuals who did not answer the question, $68.3 \%$ of men, $30.8 \%$ of women, and the single nonbinary gender respondent have children. Of the $118(40.5 \%)$ respondents without children, $24.2 \%$ of women and $9.8 \%$ of men declared not wanting children. Of note, the majority of male consultants (6 of 7) would like to have children, but the opposite was true for female consultants (5 of 8 ). All retired male consultants who replied to our survey have children, but the 2 retired female consultants do not.

Of the 134 respondents who described their childcare responsibilities, $68.6 \%$ of men and the nonbinary gender respondent said that their partner takes primary care responsibility, with only $1 \%$ of men being primary caregivers themselves. The situation for female neurosurgeons is very different, with $34.8 \%$ combining primary childcare duties with a neurosurgical career, a further $52.2 \%$ sharing childcare responsibilities with their partner, and a mere $13 \%$ who have a partner who takes care of most childcare duties. The same trends held true across all grades (Table 2).

\section{Additional Caring Responsibilities}

Only 45 respondents $(15.5 \%)$ replied that they have additional caregiving responsibilities ( 29 men, 15 women, and 1 nonbinary gender respondent). In total, 24 respondents $(53.3 \%)$ were not the predominant caregiver, but when they were, men were more likely to be the main caregiver than women ( $24.1 \%$ vs $13.3 \%)$.

\section{Called Away From Work for Caregiving Responsibilities}

A total of 120 respondents reported being called away from work for caregiving responsibilities (48.4\% of men vs $27.8 \%$ of women). When we looked at this answer for only respondents with children, women were slightly more likely to be called away than men (70.4\% vs $67.7 \%)$. Twenty-seven (22.5\%) respondents of both genders equally declared that they have faced negative consequences for being called away, with the most cited consequences being considered less committed, losing training opportunities, and being the focus of gossip at work. Four respondents (2 men and 2 women) reported having very supportive colleagues and departments.

\section{Less Than Full-Time Work or Training}

Twenty-four respondents (8.4\%) hold or have held less than full-time (LTFT) positions ( 7 consultants and 16 trainees). All current LTFT consultants are male. Of the trainees, 15 are female and 1 is male. In total, 218 respondents $(76.5 \%)$ had no intention to train or work LTFT ( $84.3 \%$ of men, $61.5 \%$ of women, and the single nonbinary gender individual). Of the 43 respondents (14.8\%) who would like to work or train LTFT, 20 were women (22\%) and 21 were men (11.4\%). Fourteen respondents (58.3\%) reported difficulties due to working LTFT, mostly related to departmental inability (or unwillingness) to adapt the neurosurgical week, fewer training opportunities, negative comments by colleagues, perceived lack of commitment, and being paid less for ultimately doing the same number of hours as a full-time employee.

\section{Disparity Between the Ways Men and Women Are Treated in Neurosurgery}

Of the 286 respondents, $44.5 \%$ feel that there is no gender disparity in neurosurgery. This represents the opinions of $52.2 \%$ of men and $29.2 \%$ of women. In total, $56.2 \%$ of female and $19.8 \%$ of male respondents believe their male colleagues are treated better in the workplace. Only 9.3\% of our respondents feel that women are treated better than men in neurosurgery (12\% of men, $1.1 \%$ of women, and 
TABLE 2. Childcare responsibilities of respondents by grade and gender

\begin{tabular}{|c|c|c|c|c|c|}
\hline Childcare Responsibility \& Grade & Male & Female & PNTS & NBG & Total \\
\hline Yes, I am responsible for most of the childcare duties & $1(1 \%)$ & $8(34.8 \%)$ & & & $9(6.7 \%)$ \\
\hline Consultant & $1(1 \%)$ & $4(17.4 \%)$ & & & $5(3.7 \%)$ \\
\hline ST3-8 (or equivalent) & & $4(17.4 \%)$ & & & $4(3.0 \%)$ \\
\hline Yes, I share childcare responsibility equally with my partner & $32(30.5 \%)$ & $12(52.2 \%)$ & $2(40 \%)$ & & $46(34.3 \%)$ \\
\hline Consultant & $17(16.2 \%)$ & $5(21.7 \%)$ & $1(20 \%)$ & & $23(17.2 \%)$ \\
\hline Post-CCT fellow (or equivalent) & $4(3.8 \%)$ & $3(13.0 \%)$ & $1(20 \%)$ & & $8(6.0 \%)$ \\
\hline ST3-8 (or equivalent) & $5(4.8 \%)$ & $4(17.4 \%)$ & & & $9(6.7 \%)$ \\
\hline ST1-2 (or equivalent) & $1(1 \%)$ & & & & $1(0.7 \%)$ \\
\hline Retired consultant & $3(2.9 \%)$ & & & & $3(2.2 \%)$ \\
\hline PNTS & $2(1.9 \%)$ & & & & $2(1.5 \%)$ \\
\hline Yes, my partner takes care of most of the childcare duties & $72(68.6 \%)$ & $3(13 \%)$ & $3(60 \%)$ & $1(100 \%)$ & $79(59 \%)$ \\
\hline Consultant & $30(28.6 \%)$ & $2(8.7 \%)$ & $1(20 \%)$ & & $33(24.6 \%)$ \\
\hline Post-CCT fellow (or equivalent) & $14(13.3 \%)$ & & & & $14(10.4 \%)$ \\
\hline ST3-8 (or equivalent) & $25(23.8 \%)$ & $1(4.3 \%)$ & $1(20 \%)$ & $1(100 \%)$ & $28(20.9 \%)$ \\
\hline ST1-2 (or equivalent) & $1(1 \%)$ & & & & $1(0.7 \%)$ \\
\hline Retired consultant & $1(1 \%)$ & & & & $1(0.7 \%)$ \\
\hline PNTS & $1(1 \%)$ & & $1(20 \%)$ & & $2(2.5 \%)$ \\
\hline Total & 105 & 23 & 5 & 1 & 134 \\
\hline
\end{tabular}

the nonbinary gender respondent). These findings hold true when assessed by grade (Table 3 ).

Forty respondents $(13.7 \%)$ chose to write free-text answers, with the 5 most common comments being that women need to outperform their male colleagues to achieve similar levels of recognition at work, bias against women is unconscious and inherent societal bias exists between men and women, disparity is due to historical preference for men but the situation is improving, women are discriminated against when they take time for childcare or work LTFT, and women feel that their ability to combine work and family life is undervalued by their colleagues.

TABLE 3. Disparity between the ways men and women are treated in neurosurgery by grade and gender

\begin{tabular}{|c|c|c|c|c|c|}
\hline Disparity \& Grade & Male & Female & PNTS & NBG & Total \\
\hline No disparity & $96(52.2 \%)$ & $26(29.2 \%)$ & $3(42.9 \%)$ & & $125(44.5 \%)$ \\
\hline Consultant & $43(23.4 \%)$ & $7(7.9 \%)$ & $2(28.6 \%)$ & & $52(18.5 \%)$ \\
\hline Post-CCT fellow (or equivalent) & $10(5.4 \%)$ & $3(3.4 \%)$ & & & $13(4.6 \%)$ \\
\hline ST3-8 (or equivalent) & $25(13.6 \%)$ & $7(7.9 \%)$ & & & $32(11.4 \%)$ \\
\hline ST1-2 (or equivalent) & $12(6.5 \%)$ & $7(7.9 \%)$ & $1(14.3 \%)$ & & $20(7.1 \%)$ \\
\hline Retired consultant & $6(3.3 \%)$ & $2(2.2 \%)$ & & & $8(2.8 \%)$ \\
\hline Other (free-text responses) & $29(15.8 \%)$ & $12(13.5 \%)$ & $1(14.3 \%)$ & & $42(14.3 \%)$ \\
\hline Men are treated better & $37(20.1 \%)$ & $50(56.2 \%)$ & $1(14.3 \%)$ & & $88(31.3 \%)$ \\
\hline Consultant & $14(7.6 \%)$ & $10(11.2 \%)$ & $1(14.3 \%)$ & & $25(8.9 \%)$ \\
\hline Post-CCT fellow (or equivalent) & $3(1.6 \%)$ & $3(3.4 \%)$ & & & $6(2.1 \%)$ \\
\hline ST3-8 (or equivalent) & $13(7.1 \%)$ & $27(30.3 \%)$ & & & $40(14.2 \%)$ \\
\hline ST1-2 (or equivalent) & $5(2.7 \%)$ & $10(11.2 \%)$ & & & $15(5.3 \%)$ \\
\hline Retired consultant & $2(1.1 \%)$ & & & & $2(0.7 \%)$ \\
\hline Women are treated better & $22(12 \%)$ & $1(1.1 \%)$ & $2(28.6 \%)$ & & $26(9.3 \%)$ \\
\hline Consultant & $3(1.6 \%)$ & & & & $3(1.1 \%)$ \\
\hline Post-CCT fellow (or equivalent) & $4(2.2 \%)$ & & $1(14.3 \%)$ & & $5(1.8 \%)$ \\
\hline ST3-8 (or equivalent) & $11(6 \%)$ & $1(1.1 \%)$ & $1(14.3 \%)$ & $1(100 \%)$ & $14(5 \%)$ \\
\hline ST1-2 (or equivalent) & $3(1.6 \%)$ & & & & $3(1.1 \%)$ \\
\hline Retired consultant & $1(0.5 \%)$ & & & & $1(0.4 \%)$ \\
\hline Total & 184 & 89 & 7 & 1 & 281 \\
\hline
\end{tabular}




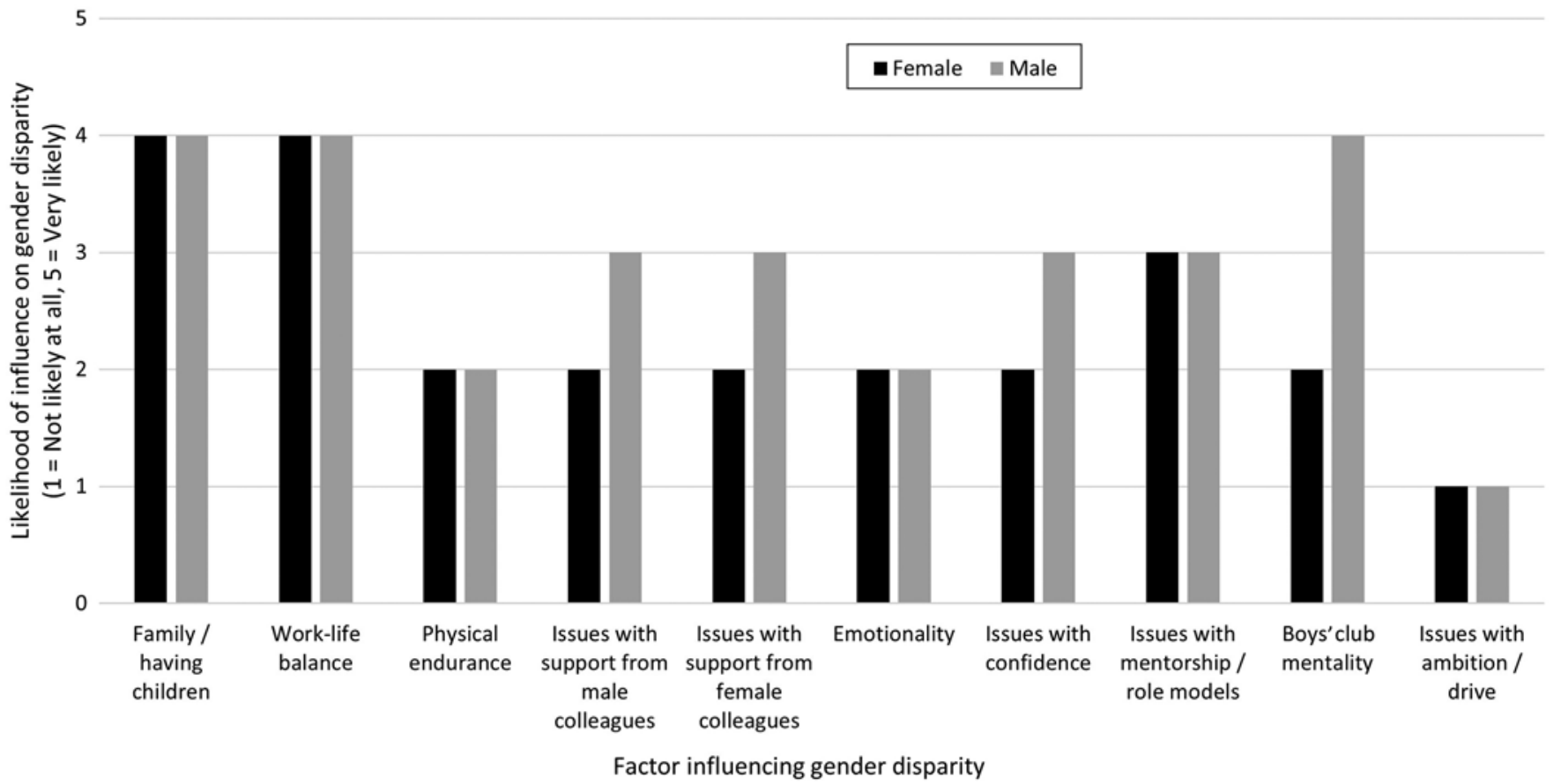

FIG. 1. Likelihood of listed options contributing to gender disparity in neurosurgery. Median values are shown.

Respondents also raised challenges of dealing with other forms of inequality due to race, ethnicity, and class.

\section{Likelihood of Listed Options Contributing to Gender Disparity in Neurosurgery}

A Likert scale of 1 (not likely at all) to 5 (very likely) was used to rank the likelihood of 10 predefined categories as contributors to gender disparity in neurosurgery (Supplemental Survey). Figure 1 shows the median scores of each category, excluding the scores of the nonbinary gender respondent due to the inability to calculate median scores. Women scored family/having children, issues with mentorship and ambition, confidence, and presence of a "boys' club" mentality higher than their male counterparts. All respondents ranked family/having children as the main contributor to gender disparity in neurosurgery. No group reported emotionality, physical endurance, or issues with ambition/drive as significant contributors to the gender gap in neurosurgery. Our male respondents did not perceive these as being major hindrances to gender equality in neurosurgery.

\section{Issues Personally Experienced or Witnessed That Could Be due to Gender Within Neurosurgery}

We received $191(65.6 \%)$ responses, with a total of 208 issues/comments (Table 4). Both men and women mentioned undermining comments made to women and issues due to maternity/parental leave as the two main issues they experienced or witnessed. The third most mentioned issue by women was the "old boys' club" mentality and feeling excluded, whereas the male cohort reported women being favored in the workplace. For our female cohort, the fourth and fifth issues were the lack of role models and women in senior positions and men being treated better at work. The male cohort diverged by reporting female stereotypes and attributes as the issues they witnessed/experienced that could affect gender disparity in neurosurgery.

\section{Suggestions to Improve Gender Inequality in Neurosurgery}

We received $221(76 \%)$ responses, with a total of 261 suggestions (Table 5). In our survey, the need to champion and support women at work as well as promote career flexibility were the two most commonly mentioned suggestions by both men and women. Our male cohort's third and fourth options were doing nothing (given that the majority felt that there was no disparity in the first place) and striving to achieve gender neutrality by regarding every member of the neurosurgical community as a surgeon rather than as an individual of a specific gender. They also mentioned the need for education in the workplace. For women, it was the need for a change of culture in the workplace, as well as a focus on education, that were their third and fourth most mentioned suggestions. Other options, such as speaking up against disparity and female networking groups, were also mentioned by both genders.

\section{Discussion}

We have conducted a UK-wide survey of neurosurgeons and neurosurgery trainees to garner opinions and attitudes toward gender differences in the UK neurosurgical community. The issue of gender disparity in the workplace is receiving wider media and societal attention across several industries and professions, including health 
TABLE 4. Issues personally experienced or witnessed that could be due to gender within neurosurgery, classified by grade and gender

\begin{tabular}{|c|c|c|c|c|c|c|c|c|c|c|c|c|c|c|c|c|}
\hline \multirow[b]{2}{*}{ Issue } & \multicolumn{3}{|c|}{ Consultant } & \multicolumn{3}{|c|}{$\begin{array}{l}\text { Post-CCT Fellow } \\
\text { (or equivalent) }\end{array}$} & \multicolumn{3}{|c|}{$\begin{array}{c}\text { ST3-8 } \\
\text { (or equivalent) }\end{array}$} & \multicolumn{2}{|c|}{$\begin{array}{c}\text { ST1-2 or Senior } \\
\text { House Officer }\end{array}$} & \multicolumn{2}{|c|}{$\begin{array}{c}\text { Retired } \\
\text { Consultant } \\
\end{array}$} & \multicolumn{2}{|c|}{ PNTS } & \multirow[b]{2}{*}{ Total } \\
\hline & $\mathrm{F}$ & M & PNTS & $\mathrm{F}$ & M & PNTS & $\mathrm{F}$ & M & PNTS & $\mathrm{F}$ & M & $\mathrm{F}$ & M & M & PNTS & \\
\hline $\begin{array}{l}\text { Inappropriate comments or } \\
\text { undermining or sexual harassment }\end{array}$ & 4 & 3 & & & & & 12 & 5 & 1 & 1 & 1 & & 2 & & & 29 \\
\hline Female maternity/parenting issues & 3 & 3 & & 2 & 1 & & 7 & 4 & & 3 & 2 & & 2 & & & 27 \\
\hline Exclusion/boys' club attitude & 4 & 3 & & & & & 9 & 2 & & 2 & & & & & & 20 \\
\hline Female stereotypes & & 4 & & & 3 & & 4 & 2 & & 5 & 1 & & & & & 19 \\
\hline Childcare regardless of gender & 1 & 1 & 1 & 1 & 1 & & 5 & 4 & & & & 1 & 2 & & & 17 \\
\hline $\begin{array}{l}\text { Lack of role models/women in } \\
\text { senior positions }\end{array}$ & 2 & & & & & & 4 & 4 & & 4 & 3 & & & & & 17 \\
\hline Female attributes & 3 & 7 & & & 1 & & 1 & 1 & & 1 & 1 & & 1 & & & 16 \\
\hline Males treated better & 2 & 1 & & & & & 4 & & & 4 & 2 & & 1 & & & 14 \\
\hline Females treated better & & 2 & & & 2 & & & 3 & 2 & & 1 & & 2 & 1 & & 13 \\
\hline Other & 2 & 2 & & & & & 2 & 1 & & & & & 1 & & & 8 \\
\hline Positive discrimination & & & & & & 1 & 1 & 3 & 1 & & 1 & & & & 1 & 8 \\
\hline Patients/nurses treating differently & 1 & 1 & & & & & 1 & 2 & & 2 & & & & & & 7 \\
\hline Females feel they have to try harder & & 2 & & & & & 1 & 1 & & & 1 & & & & & 5 \\
\hline $\begin{array}{l}\text { Lack of support/isolation at } \\
\text { consultant level for females }\end{array}$ & 3 & 1 & & & & & & & & & & & & & & 4 \\
\hline LTFT issues & & 1 & & & & & & 2 & & & 1 & & & & & 4 \\
\hline Total & 25 & 31 & 1 & 3 & 8 & 1 & 51 & 34 & 4 & 22 & 14 & 1 & 11 & 1 & 1 & 208 \\
\hline
\end{tabular}

care, and this is the first large-scale survey of the neurosurgical community in the UK.

\section{Workforce Data}

As of March 2020, a total of 470 consultants and associate specialists were identified by a census conducted by the UK and Eire Workforce Planning Committee for Neurosurgery (K. Whitehouse, written communication, October 28, 2020). Gender information was provided for 448 consultants, and of these 41 were female. This equates to $9 \%$ of all consultant neurosurgeons in the UK and Ireland being female. This is consistent with National Health Service (NHS) Digital neurosurgical workforce statistics for England (Table 6), with the percentage of female consultant neurosurgeons remaining around $8 \%$ between 2010 and $2020 .^{7,8}$

In the same period, the neurosurgical workforce grew very significantly in England, with the number of consultants increasing by $55 \%$ from 236 to 366. Despite a net recruitment of 130 additional consultants, the percentage of women barely increased from $7.2 \%(\mathrm{n}=17)$ to $7.9 \%(\mathrm{n}=$ 29) of the total. ${ }^{7,8}$ It is also worth noting that this occurred

TABLE 5. Suggestions to improve gender inequality in neurosurgery classified by grade and gender

\begin{tabular}{|c|c|c|c|c|c|c|c|c|c|c|c|c|c|c|c|c|}
\hline \multirow[b]{2}{*}{ Suggestion } & \multicolumn{3}{|c|}{ Consultant } & \multicolumn{3}{|c|}{$\begin{array}{l}\text { Post-CCT Fellow } \\
\text { (or equivalent) }\end{array}$} & \multicolumn{4}{|c|}{$\begin{array}{c}\text { ST3-8 } \\
\text { (or equivalent) }\end{array}$} & \multicolumn{2}{|c|}{$\begin{array}{c}\text { ST1-2 or Senior } \\
\text { House Officer }\end{array}$} & \multicolumn{2}{|c|}{$\begin{array}{c}\text { Retired } \\
\text { Consultant }\end{array}$} & \multirow{2}{*}{$\begin{array}{c}\text { PNTS } \\
\text { (all male) }\end{array}$} & \multirow[b]{2}{*}{ Total } \\
\hline & $\mathrm{F}$ & M & PNTS & $\mathrm{F}$ & M & PNTS & $\mathrm{F}$ & M & Other & PNTS & $\mathrm{F}$ & $M$ & $\mathrm{~F}$ & $\mathrm{M}$ & & \\
\hline Champion women \& support & 9 & 14 & & 2 & 1 & & 14 & 11 & & & 6 & 7 & & 2 & & 66 \\
\hline Career flexibility & 3 & 13 & & 1 & 7 & 1 & 10 & 11 & & 1 & 6 & 3 & & 2 & & 58 \\
\hline Culture change & 2 & 3 & 2 & 2 & 3 & 1 & 10 & 4 & & & 4 & 4 & & 1 & & 36 \\
\hline Education & 4 & 3 & & 1 & 1 & & 8 & 4 & & 1 & 2 & 3 & 1 & & & 28 \\
\hline Do nothing & 1 & 9 & & 1 & 2 & & 2 & 3 & & & & & & 1 & 2 & 21 \\
\hline Gender neutrality & 1 & 8 & & & & & & 4 & 1 & & 1 & 2 & 1 & 3 & & 21 \\
\hline Other & 1 & 2 & & & 2 & & 1 & 4 & & & 1 & & & 2 & 1 & 14 \\
\hline Speak up & 2 & 2 & & & 1 & & 2 & 1 & & 1 & 1 & 1 & & 1 & & 12 \\
\hline Female networking groups & 1 & & & & & & & 2 & & & & 1 & & & & 4 \\
\hline Safe space to raise issues & & & & & & & & & & & 1 & & & & & 1 \\
\hline Total & 24 & 54 & 2 & 7 & 17 & 2 & 47 & 44 & 1 & 3 & 22 & 21 & 2 & 12 & 3 & 261 \\
\hline
\end{tabular}


TABLE 6. Neurosurgical female workforce statistics, 2010-2020

\begin{tabular}{|c|c|c|c|c|c|c|c|c|c|c|c|c|}
\hline \multirow[b]{2}{*}{ Grade } & \multicolumn{12}{|c|}{$\%$ Female } \\
\hline & $\begin{array}{c}\text { March } \\
2010\end{array}$ & $\begin{array}{c}\text { March } \\
2011\end{array}$ & $\begin{array}{c}\text { March } \\
2012\end{array}$ & $\begin{array}{c}\text { March } \\
2013\end{array}$ & $\begin{array}{c}\text { March } \\
2014\end{array}$ & $\begin{array}{c}\text { March } \\
2015\end{array}$ & $\begin{array}{c}\text { March } \\
2016\end{array}$ & $\begin{array}{c}\text { March } \\
2017\end{array}$ & $\begin{array}{c}\text { March } \\
2018\end{array}$ & $\begin{array}{l}\text { May } \\
2019\end{array}$ & $\begin{array}{l}\text { Sept } \\
2019\end{array}$ & $\begin{array}{l}\text { May } \\
2020\end{array}$ \\
\hline Consultant & $7.20 \%$ & $6.58 \%$ & $7.92 \%$ & $6.95 \%$ & $6.99 \%$ & $7.64 \%$ & $6.40 \%$ & $7.26 \%$ & $8.16 \%$ & $7.95 \%$ & $8.36 \%$ & $7.92 \%$ \\
\hline Specialty registrar & $19.20 \%$ & $17.12 \%$ & $18.81 \%$ & $18.81 \%$ & $20.25 \%$ & $20.36 \%$ & $19.65 \%$ & $23.12 \%$ & $23.14 \%$ & $25.47 \%$ & $25.13 \%$ & $22.28 \%$ \\
\hline CT & $25.76 \%$ & $21.74 \%$ & $25.00 \%$ & $27.42 \%$ & $34.33 \%$ & $32.73 \%$ & $26.09 \%$ & $38.30 \%$ & $27.94 \%$ & $31.82 \%$ & $28.85 \%$ & $26.96 \%$ \\
\hline Foundation doctors & $32.61 \%$ & $38.18 \%$ & $39.62 \%$ & $46.00 \%$ & $37.74 \%$ & $46.00 \%$ & $37.25 \%$ & $42.86 \%$ & $62.50 \%$ & $47.73 \%$ & $53.85 \%$ & $42.22 \%$ \\
\hline Other & $7.69 \%$ & $9.52 \%$ & $10.00 \%$ & $14.29 \%$ & $13.33 \%$ & $25.00 \%$ & $25.00 \%$ & $16.67 \%$ & $18.75 \%$ & $13.04 \%$ & $9.09 \%$ & $10.53 \%$ \\
\hline Total & $16.17 \%$ & $15.29 \%$ & $16.81 \%$ & $16.99 \%$ & $17.72 \%$ & $18.13 \%$ & $16.09 \%$ & $18.75 \%$ & $19.73 \%$ & $19.89 \%$ & $19.85 \%$ & $17.90 \%$ \\
\hline
\end{tabular}

Data obtained from NHS Digital7.8 and K. Whitehouse, FRCS, personal communication, October 28, 2020.

despite the consistently higher percentage of women in training positions $(25.8 \%-27 \%$ of core trainees [CTs] and $19.2 \%-22.3 \%$ of specialist trainees [STs]) throughout the same period (Table 6). This may be because women take longer to complete training-because of maternity leave, for example-but it raises concerns of a higher attrition rate for women. For example, Renfrow et al. ${ }^{9}$ reported a $17 \%$ female attrition rate compared to a $5.3 \%$ male attrition rate for neurosurgery residents in the US between 2000 and 2009.

Underrepresentation of women at the consultant level is not unique to neurosurgery or the UK. Classic "maledominated" specialties, like cardiothoracic and trauma and orthopedic surgery, show below-average percentages of female consultants: $8.8 \%$ and $6.5 \%$, respectively, versus a $14.5 \%$ average (Table 7). ${ }^{10}$ We note the slight inconsistency in the different NHS Digital data sets, which cannot be explained totally by different dates - for example, one data set reports that $8.16 \%$ of consultants are female ${ }^{6}$ and the other reports $6.8 \% .{ }^{10}$ However, we have decided that it is beneficial to include the second data set because it is consistent (but not identical) and allows us to compare neurosurgery to other surgical specialties. Comparing neurosurgery in the UK to other parts of the world, we found similar percentages as Steklacova et al., ${ }^{11}$ who reported that $12 \%$ of neurosurgeons across Europe were women in 2017 (highest in Italy with 36\%, lowest in Kosovo and Cyprus with $0 \%$ ), and Renfrow et al., ${ }^{9}$ who reported $12.1 \%$ in the US and Canada between 2000 and 2009. Focusing on the proportions of female residents and board-certified neurosurgeons, Renfrow et al. ${ }^{9}$ reported these proportions to be $16.3 \%$ and $6.1 \%$, respectively, in the US in 2016, whereas Steklacova et al. ${ }^{11}$ reported proportions of $32 \%$ and $11 \%$ across Europe in the same year (18\% of trainees and $8 \%$ of consultant equivalents in the UK).

\section{Survey Findings}

Based on the UK census, we estimate that we surveyed $15.6 \%$ (70/448) of male and $51.2 \%$ (21/41) of female consultants. It is difficult to obtain reliable numbers for other grades, but we provided estimates by scaling data from NHS Digital for England by $30 \%$ (i.e., the ratio we see by comparing the number of UK consultants according to the UK census to the number according to NHS Digital for England). This allowed us to estimate that our survey responses accounted for approximately $20 \%$ of male and $45 \%$ of female staff with ST and CT grades.

\section{Family Planning and Childcare}

Challenges due to family planning and childcare are a recurrent theme throughout our survey results. Maehara et

TABLE 7. Surgical workforce statistics for consultants, specialty registrars, and CTs, January 2018

\begin{tabular}{|c|c|c|c|c|c|c|c|c|c|c|c|c|}
\hline \multirow[b]{2}{*}{ Specialty } & \multicolumn{3}{|c|}{ All Grades } & \multicolumn{3}{|c|}{ Consultant } & \multicolumn{3}{|c|}{ Specialty Registrar } & \multicolumn{3}{|c|}{ CT } \\
\hline & Female & Male & $\%$ Female & Female & Male & $\%$ Female & Female & Male & $\%$ Female & Female & Male & $\%$ Female \\
\hline All surgical groups & 6,505 & 17,281 & $27.3 \%$ & 1,389 & 8,164 & $14.5 \%$ & 2,013 & 4,394 & $31.4 \%$ & 721 & 1,239 & $36.8 \%$ \\
\hline Cardiothoracic surgery & 166 & 738 & $18.4 \%$ & 33 & 343 & $8.8 \%$ & 75 & 281 & $21.1 \%$ & 29 & 41 & $41.4 \%$ \\
\hline General surgery & 2,341 & 4,819 & $32.7 \%$ & 388 & 2,051 & $15.9 \%$ & 563 & 1,061 & $34.7 \%$ & 268 & 392 & $40.6 \%$ \\
\hline Neurosurgery & 162 & 671 & $19.4 \%$ & 22 & 301 & $6.8 \%$ & 84 & 289 & $22.5 \%$ & 21 & 54 & $28.0 \%$ \\
\hline Ophthalmology & 1,126 & 1,769 & $38.9 \%$ & 403 & 957 & $29.6 \%$ & 351 & 385 & $47.7 \%$ & 29 & 35 & $45.3 \%$ \\
\hline Otolaryngology & 565 & 1,291 & $30.4 \%$ & 115 & 633 & $15.4 \%$ & 211 & 277 & $43.2 \%$ & 79 & 88 & $47.3 \%$ \\
\hline Pediatric surgery & 155 & 264 & $37.0 \%$ & 52 & 141 & $26.9 \%$ & 77 & 89 & $46.4 \%$ & 14 & 16 & $46.7 \%$ \\
\hline Plastic surgery & 380 & 819 & $31.7 \%$ & 99 & 401 & $19.8 \%$ & 174 & 258 & $40.3 \%$ & 79 & 88 & $47.3 \%$ \\
\hline Trauma \& orthopedic surgery & 1,070 & 5,145 & $17.2 \%$ & 166 & 2,390 & $6.5 \%$ & 321 & 1,390 & $18.8 \%$ & 147 & 417 & $26.1 \%$ \\
\hline Urology & 465 & 1,505 & $23.6 \%$ & 89 & 804 & $10.0 \%$ & 133 & 305 & $30.4 \%$ & 46 & 94 & $32.9 \%$ \\
\hline Vascular surgery & 78 & 274 & $22.2 \%$ & 23 & 154 & $13.0 \%$ & 25 & 59 & $29.8 \%$ & 9 & 14 & $39.1 \%$ \\
\hline
\end{tabular}

Data obtained from NHS Digital..$^{10}$ 
al. ${ }^{12}$ surveyed women who quit full-time employment as neurosurgeons in Japan and reported difficulty balancing motherhood and a neurosurgical career as the main reason for attrition. Rangel et al. ${ }^{13}$ reached similar conclusions in the US, warning that the challenges of having children during training could significantly impact the workforce.

Women in our cohort reported juggling demanding work duties with childcare responsibilities because they were either the main caregiver or sharing duties equally with their partner. In contrast, the majority of male neurosurgeons do not report having to do the same. This is corroborated by Grandis et al., ${ }^{14}$ who found that male otolaryngologists rely more on their partners for childcare than their female colleagues. Jolly et al. ${ }^{15}$ reported that highachieving male physician-researchers were more likely to have partners who were not employed full-time, unlike their female counterparts, thereby indirectly reinforcing this statement. The World Health Organization ${ }^{16}$ highlights the greater burden of household work, responsibility for family, maternity leave, childcare, and time for breastfeeding as some of the causes of occupational segregation for women..$^{17,18}$

Although most respondents without children state that they would like to have a family, the proportion is lower for women than men. This potentially suggests that women feel they have to choose between a neurosurgical career and having a family. Championing role models and increasing the visibility of women who successfully combine a neurosurgical career and a family life may help shift this balance in the future.

\section{Mentorship and Women in Leading Positions}

Mentorship contributes to higher career satisfaction rates and academic productivity, ${ }^{19-22}$ and it is an influential factor in guiding specialty choice for medical students. ${ }^{23,24}$ As a result, women in our survey and worldwide ${ }^{25-27}$ strive for better mentorship in the workplace. Although some countries, like the US, seem to have better established mentoring schemes, ${ }^{22,28,29}$ more needs to be done in the UK. RCS Eng offers a guide on mentoring ${ }^{30}$ and the Royal College of Physicians and Surgeons of Glasgow offers mentoring schemes and support to both mentors and mentees ${ }^{31}$ but organizations are often left to set up their own schemes. ${ }^{32}$ The University College London Women in Surgery Mentoring Scheme is targeted at students, ${ }^{33}$ but more is needed for existing neurosurgical trainees and consultants. In Switzerland, just over half the female surgeons and trainees have a mentor. ${ }^{34}$ It is unclear whether it is more beneficial for women to have female mentors. ${ }^{35,36}$ In the study by Kaderli et al., ${ }^{34}$ mentor-mentee relationship and satisfaction of mentees with career advancement support was not rated higher with female mentors. The low number of senior female neurosurgeon $\mathrm{s}^{25}$ should therefore not hinder mentorship. Men can be equally effective mentors to female neurosurgeons and should be encouraged to take up these roles.

As highlighted by our survey, there is a need for more women in leadership and academic positions in neurosurgery. ${ }^{26,27,37}$ According to the SBNS, 2 of 56 academic neurosurgeons are women, ${ }^{38}$ and in the US, women holding full professor positions are a minority $(5.84 \%) .{ }^{27}$ Of the 10 elected SBNS council members, only 1 is a woman, ${ }^{39}$ and 3 of 13 BNTA committee representatives are female. ${ }^{40}$ With the launch of inclusivity schemes, such as the Lady Estelle Wolfson Emerging Leaders Fellowship, ${ }^{41}$ more women are encouraged to apply for senior and leadership roles. In 2019, the SBNS welcomed its first "Women in Neurosurgery" forum run by two female neurosurgical trainees ${ }^{42}$ where neurosurgeons of all genders and grades had the opportunity to network and discuss issues they face at various stages of their careers. We hope that the interest generated by this forum ${ }^{42}$ will encourage the creation of a new SBNS committee, similar to the "Diversity in Neurosurgery Task Force" of the European Association of Neurosurgical Societies, ${ }^{43}$ to foster a more inclusive neurosurgical environment.

\section{"Old Boys' Club" Mentality}

An independent investigation of reports of sexism and sexual harassment at the British Medical Association found a lingering "old boys' club" mentality ${ }^{44}$ with some women feeling "undervalued, ignored and patronised because they are women." Women surveyed by the Association of Surgeons of Great Britain and Ireland in 2017,45 as well as those in our cohort, raised similar concerns. It is interesting to notice that men do not tend to view this as a contributor to gender disparity in neurosurgery. However, it is important to not demonize men and acknowledge the fact that bias can sometimes be unintentional. Salles et al. ${ }^{46}$ conducted the Implicit Association Test and identified clear and consistent gender bias in surgery that can affect the career success of women. Coe et al ${ }^{47}$ highlighted the importance of inclusive leadership positions, self-awareness about implicit bias from men and women alike, and academic societies taking a role in cultural change and advocating for gender equality. Dossa and Baxter ${ }^{88}$ stated that the ubiquity of gender bias needs to be addressed if we hope to give women the same opportunities as men when it comes to leading a successful and fulfilling surgical career. For example, we hope to see equality, diversity, and unconscious bias courses required for people involved in hiring and training neurosurgeons.

\section{Perceived Discrimination Against Men as an Emerging Theme}

The former president of RCS Eng has said, "Quotas may be needed to increase the number of women working in surgery if other interventions fail, ${ }^{, 49}$ but some of our male respondents fear that women are benefitting, ahead of them, from positive treatment for consultant positions in neurosurgery. Although positive discrimination is prohibited under the Equality Act $2010,{ }^{50}$ positive actions taken to address imbalance of opportunities are permitted. The 2017 study by Besley et al..$^{51}$ on the quality of work in the Swedish political system found that quotas for female workers raised the competence level of their male counterparts. The reason for this change was the resignation of less competent males; therefore, quotas actually improved overall levels of competence. We all aspire to meritocratic career advancement. Although this paper is aimed at raising awareness of low female representation in neurosurgery, it is important to acknowledge the impact that measures to address gender imbalance may have on men, as 
ultimately the success of such measures also requires the full support of neurosurgeons of all genders.

\section{Conclusions and Future Directions}

Despite an increase in overall staff, the proportion of female staff in UK neurosurgery has remained flat over the past decade. This survey provides a broad overview of current opinions and attitudes about the gender gap in UK neurosurgery, and the majority of women reported being treated worse than their male colleagues. More work is needed to deepen our understanding of this situation, and better UK data is needed to monitor the progress of women in neurosurgery.

Future work should be targeted to identify and address specific issues holding back the realization of gender equality in UK neurosurgery. The implementation of any solutions and changes to address culture, behaviors, and biases will require strong leadership and political will from the highest authorities in the profession, as well as engagement from all genders at all levels. UK neurosurgery could also benefit from collaboration with other surgical specialties and neurosurgeons in other countries given the common issues faced.

As Spetzler said in his landmark paper regarding the gender gap issue in neurosurgery, "The primary goal should be, as it always has been, to attract the best and brightest candidates and leaders who are passionate about neurosurgery, regardless of their gender or any other minority status."6 We must all work together to continue the promotion of cultural change and awareness of diversity in neurosurgery.

\section{Acknowledgments}

We would like to thank all the individuals who replied to our survey for their honest opinions.

\section{References}

1. Bademci G. First illustrations of female "Neurosurgeons" in the fifteenth century by Serefeddin Sabuncuoglu. Neurocirugia (Astur). 2006;17(2):162-165.

2. Ellis H. Notable women in healthcare: Elizabeth GarrettAnderson. J Perioper Pract. 2008;18(10):451.

3. Gilkes CE. An account of the life and achievements of Miss Diana Beck, neurosurgeon (1902-1956). Neurosurgery. 2008; 62(3):738-742.

4. General Medical Council. Medical school reports. Published June 7, 2018. Accessed January 20, 2021. https://www.gmcuk.org/education/reports-and-reviews/medical-school-reports

5. Royal College of Surgeons of England. Women in surgery statistics. Accessed January 20, 2021. https://www.rcseng. ac.uk/careers-in-surgery/women-in-surgery/statistics/

6. Spetzler RF. Progress of women in neurosurgery. Asian J Neurosurg. 2011;6(1):6-12.

7. NHS Digital. NHS Digital NHS Hospital \& Community Health Service (HCHS) workforce statistics. Accessed January 20, 2021. https://digital.nhs.uk/ search?query=neurosurgery

8. NHS Digital. HCHS Drs in neurosurgery by gender and grade. Accessed January 20, 2021. https://digital.nhs.uk/ data-and-information/supplementary-information/2020/hchsdrs-in-neurosurgery-by-gender-and-grade-may-19-sep-19-may20-ah3452
9. Renfrow JJ, Rodriguez A, Liu A, et al. Positive trends in neurosurgery enrollment and attrition: analysis of the 2000-2009 female neurosurgery resident cohort. J Neurosurg. 2016; 124(3):834-839.

10. NHS Digital. Narrowing of NHS gender divide but men still the majority in senior roles. Accessed January 20, 2021. https://digital.nhs.uk/news-and-events/news/narrowing-ofnhs-gender-divide-but-men-still-the-majority-in-senior-roles

11. Steklacova A, Bradac O, de Lacy P, Benes V. E-WIN Project 2016: evaluating the current gender situation in neurosurgery across Europe-an interactive, multiple-level survey. World Neurosurg. 2017;104:48-60.

12. Maehara T, Kamiya K, Fujimaki T, et al. A questionnaire to assess the challenges faced by women who quit working as full-time neurosurgeons. World Neurosurg. 2020;133: 331-342.

13. Rangel EL, Smink DS, Castillo-Angeles M, et al. Pregnancy and motherhood during surgical training. JAMA Surg. 2018; 153(7):644-652.

14. Grandis JR, Gooding WE, Zamboni BA, et al. The gender gap in a surgical subspecialty: analysis of career and lifestyle factors. Arch Otolaryngol Head Neck Surg. 2004;130(6): 695-702.

15. Jolly S, Griffith KA, DeCastro R, et al. Gender differences in time spent on parenting and domestic responsibilities by high-achieving young physician-researchers. Ann Intern Med. 2014;160(5):344-353.

16. World Health Organization. Working Paper on Gender \& Equity in the Health and Social Care Workforce. WHO; 2018. Accessed January 20, 2021. https://www.who.int/hrh/ news/2018/GEHworking-paper-ZeroDraft.pdf

17. Boulis A, Jacobs J, Veloski JJ. Gender segregation by specialty during medical school. Acad Med. 2001;76(10)(suppl): S65-S67.

18. Diderichsen S, Johansson EE, Verdonk P, et al. Few gender differences in specialty preferences and motivational factors: a cross-sectional Swedish study on last-year medical students. BMC Med Educ. 2013;13:39.

19. Steiner JF, Curtis P, Lanphear BP, et al. Assessing the role of influential mentors in the research development of primary care fellows. Acad Med. 2004;79(9):865-872.

20. Ramondetta LM, Bodurka DC, Tortolero-Luna G, et al. Mentorship and productivity among gynecologic oncology fellows. J Cancer Educ. 2003;18(1):15-19.

21. Rivera JA, Levine RB, Wright SM. Completing a scholarly project during residency training. Perspectives of residents who have been successful. J Gen Intern Med. 2005;20(4): 366-369.

22. Khan NR, Derstine PL, Gienapp AJ, et al. A survey of neurological surgery residency program mentorship practices compared to Accreditation Council for Graduate Medical Education resident outcome data. Neurosurgery. 2020;87(5): E566-E572.

23. Osborn EH. Factors influencing students' choices of primary care or other specialties. Acad Med. 1993;68(7):572-574.

24. Huq S, Khalafallah AM, Ishida W, et al. Recruiting medical students to neurosurgery through a focused neuroanatomy lab initiative. World Neurosurg. 2020;137:e535-e546.

25. Benzil DL, Abosch A, Germano I, et al. The future of neurosurgery: a white paper on the recruitment and retention of women in neurosurgery. J Neurosurg. 2008;109(3):378-386.

26. Odell T, Toor H, Takayanagi A, et al. Gender disparity in academic neurosurgery. Cureus. 2019;11(5):e4628.

27. Renfrow JJ, Rodriguez A, Wilson TA, et al. Tracking career paths of women in neurosurgery. Neurosurgery. 2018;82(4): 576-582.

28. American Association of Neurological Surgeons. AANS mentoring program. Accessed January 20, 2021. https://www. aans.org/Trainees/Residents-Fellows/Mentoring-Program 
29. Sanfey H, Hollands C, Gantt NL. Strategies for building an effective mentoring relationship. Am J Surg. 2013;206(5): 714-718.

30. Royal College of Surgeons of England. Mentoring: A Guide to Good Practice. Accessed January 20, 2021. https://www. rcseng.ac.uk/standards-and-research/standards-and-guidance/ good-practice-guides/mentoring/

31. Royal College of Physicians and Surgeons of Glasgow. Mentorship programme. Accessed January 20, 2021. https://rcpsg. ac.uk/college/this-is-what-we-do/support-and-mentorship/ mentorship-programme

32. Royal College of Surgeons of England. Mentoring schemes. Accessed January 20,2021. https://www.rcseng.ac.uk/ standards-and-research/support-for-surgeons-and-services/ professional-support-for-surgeons/mentoring/mentoringschemes/

33. British Association of Paediatric Surgeons. UCL women in surgery mentoring scheme. Accessed January 20, 2021. https: //www.baps.org.uk/news/announcements/ucl-women-insurgery-mentoring-scheme/

34. Kaderli R, Muff B, Stefenelli U, Businger A. Female surgeons' mentoring experiences and success in an academic career in Switzerland. Swiss Med Wkly. 2011;141:w13233.

35. Levinson W, Kaufman K, Clark B, Tolle SW. Mentors and role models for women in academic medicine. West $\mathrm{J}$ Med. 1991;154(4):423-426.

36. Buddeberg-Fischer B, Vetsch E, Mattanza G. Career support in medicine-experiences with a mentoring program for junior physicians at a university hospital. Psychosoc Med. 2004;1:Doc04.

37. Wolfert C, Rohde V, Mielke D, Hernández-Durán S. Female neurosurgeons in Europe-on a prevailing glass ceiling. World Neurosurg. 2019;129:460-466.

38. Society of British Neurological Surgeons. Academic neurosurgeons. Accessed January 20, 2021. https://www.sbns.org. uk/index.php/research/academic-neurosurgeons/

39. Society of British Neurological Surgeons. SBNS Council. Accessed January 20, 2021. https://www.sbns.org.uk/index. php/councils/

40. British Neurosurgical Trainees' Association. Committee. Accessed January 20, 2021. https://e1v1m1.co.uk/?page_id=42

41. Royal College of Surgeons of England. The Lady Estelle Wolfson Emerging Leaders Fellowship. Accessed January 20, 2021. https://www.rcseng.ac.uk/careers-in-surgery/ women-in-surgery/the-lady-estelle-wolfson-emergingleaders-fellowship/

42. Society of British Neurological Surgeons. SBNS Summer Newsletter-August 2019. Accessed January 20, 2021. https: //www.sbns.org.uk/index.php/policies-and-publications/ newsletter/

43. European Association of Neurosurgical Societies. Diversity in neurosurgery task force. Accessed January 20, 2021. https: //www.eans.org/page/Diversity_Task_Force
44. Broyd N. Report finds lingering 'old boys' club' culture at BMA. Medscape News UK. October 18, 2019. Accessed January 20, 2021. https://www.medscape.com/ viewarticle/920005

45. Bellini MI, Graham Y, Hayes C, et al. A woman's place is in theatre: women's perceptions and experiences of working in surgery from the Association of Surgeons of Great Britain and Ireland women in surgery working group. BMJ Open. 2019;9(1):e024349.

46. Salles A, Awad M, Goldin L, et al. Estimating implicit and explicit gender bias among health care professionals and surgeons. JAMA Netw Open. 2019;2(7):e196545.

47. Coe IR, Wiley R, Bekker LG. Organisational best practices towards gender equality in science and medicine. Lancet. 2019;393(10171):587-593.

48. Dossa F, Baxter NN. Reducing gender bias in surgery. $\mathrm{Br} J$ Surg. 2018;105(13):1707-1709.

49. Rimmer A. Quotas may be needed to get more women surgeons, college president says. BMJ. 2016;354:i3685.

50. The National Archives. Equality Act 2010. Accessed January 20, 2021. https://www.legislation.gov.uk/ukpga/2010/15/ part/11/chapter/2

51. Besley T, Folke O, Persson T, Rickne J. Gender quotas and the crisis of the mediocre man: theory and evidence from Sweden. Am Econ Rev. 2017;107(8):2204-2242.

\section{Disclosures}

The authors report no conflict of interest concerning the materials or methods used in this study or the findings specified in this paper.

\section{Author Contributions}

Conception and design: Amarouche, Uberti, Singh. Acquisition of data: Amarouche, Uberti, Evans. Analysis and interpretation of data: Amarouche, Uberti, Evans. Drafting the article: Amarouche, Uberti, Evans. Critically revising the article: all authors. Reviewed submitted version of manuscript: all authors. Approved the final version of the manuscript on behalf of all authors: Amarouche. Statistical analysis: Amarouche, Evans. Study supervision: Amarouche, Singh.

\section{Supplemental Information Online-Only Content}

Supplemental material is available online.

Supplemental Survey. https://thejns.org/doi/suppl/10.3171/ 2020.12.FOCUS20957.

\section{Correspondence}

Meriem Amarouche: John Radcliffe University Hospital, Oxford, United Kingdom. meriem.amarouche@nhs.net. 